\title{
Adult Embryonal Tumor with Multilayered Rosettes, C19MC-Altered
}

National Cancer Institute

\section{Source}

National Cancer Institute. Adult Embryonal Tumor with Multilayered Rosettes, C19MC-

Altered. NCI Thesaurus. Code C8290.

An embryonal tumor with multilayered rosettes, C19MC-altered, occurring in adults. 